\title{
PROPRIEDADES DO MODAL DEÔNTICO OUGHT-TO-BE
}

\author{
Núbia Ferreira RECH ${ }^{*}$ \\ Giuseppe VARASCHIN**
}

- RESUMO: Neste artigo, discutimos diferentes conceitos de obrigação a partir da distinção estabelecida por Feldman (1986): (i) interpretação ought-to-be, que envolve uma propriedade de um estado de coisas que deve ocorrer; e (ii) interpretação ought-to-do, que relaciona um agente a um estado de coisas. Supomos que tal distinção conceitual resulta de diferenças estruturais. Nessa linha, seguimos Brennan (1993) e Hacquard (2006, 2010). Como ainda não há na literatura uma proposta de representação estrutural que dê conta da interpretação ought-to-be, buscamos evidências no português brasileiro para depreender mais precisamente a posição em que o deôntico é concatenado na estrutura para gerar essa interpetação. Analisamos fatores como orientação dos deônticos, relação com outros núcleos modais e com categorias de tempo e aspecto. Nossos testes apontaram para a existência de um deôntico alto (ought-to-be). Este exibe propriedades de um ato de fala diretivo, é orientado para um agente na situação de fala (geralmente o addressee) e não carrega marcas de tempo ou aspecto. Embora o deôntico ought-to-be não compartilhe todas essas propriedades com o modal epistêmico, há evidências de que esses modais ocupam a mesma posição na estrutura. Por fim, propomos distinguir deônticos ought-to-be de epistêmicos e de deônticos ought-to-do a partir de dois traços: agentividade $[\mathrm{Ag}]$ e asserção [Assert].

- PALAVRAS-CHAVE: Modalidade Deôntica. Deônticos Ought-to-be. Hierarquia de Cinque. Checagem de traços.

\section{Introdução}

Uma característica marcante dos indicadores de modalidade através das línguas é o fato de eles serem sistematicamente polissêmicos. Este ponto - que foi reconhecido por diversas abordagens linguísticas (JACKENDOFF, 1972; SWEETSTER, 1990; PALMER, 2001; CINQUE, 2006; KRATZER, 2012) - é um desafio para qualquer proposta que tenha pretensões explanatórias, na medida em que deflagra a implausibilidade

\footnotetext{
Universidade Federal de Santa Catarina (UFSC), Departamento de Língua e Literatura Vernáculas, Florianópolis, Santa Catarina, Brasil. nubia.rech@ufsc.br. ORCID: 0000-0002-9278-2702.

** Universidade Federal de Santa Catarina (UFSC), Departamento de Língua e Literatura Vernáculas, Florianópolis, Santa Catarina, Brasil. giuseppe.varaschin@gmail.com. ORCID: 0000-0003-1446-2700
} 
de soluções fáceis, que aleguem uma simples ambiguidade lexical. Quando uma regularidade descritiva é constatada em várias línguas tipologicamente diversas, é geralmente sinal de que algum princípio mais profundo da gramática está em jogo. $\mathrm{Na}$ perspectiva gerativa, e, mais especificamente, cartográfica que adotamos, a aposta é que essa regularidade deriva de propriedades sintáticas das línguas (CINQUE; RIZZI, 2008). A ideia geral é que a sintaxe pode desempenhar um papel relevante - ao lado da semântica - na definição do tipo de modalidade.

Neste artigo, focamos em um aspecto pequeno, mas relevante, desse problema geral. Nosso objetivo aqui é discutir, do ponto de vista do português brasileiro, os diferentes tipos de deônticos a partir de uma distinção conceitual discutida por Feldman (1986): a distinção entre (i) a interpretação ought-to-be, que envolve uma propriedade de um estado de coisas que deve ocorrer; e (ii) a interpretação ought-to-do, que relaciona um agente a um estado de coisas. Tentaremos mostrar que essa distinção conceitual resulta de diferenças estruturais. Nessa linha, seguimos autores como Brennan (1993) e Hacquard $(2006,2010)$, que associam a interpretação ought-to-be a uma posição alta na estrutura da sentença; e a ought-to-do, a uma posição baixa.

Pelo que sabemos, na literatura ainda não há uma proposta de representação estrutural que dê conta da interpretação ought-to-be. Procuramos dar os primeiros passos nessa direção, buscando evidências no português brasileiro para depreender mais precisamente a posição em que o deôntico ought-to-be é concatenado à estrutura. Para isso, analisamos fatores como a orientação dos deônticos, sua relação com outros núcleos modais e também sua relação com categorias de tempo e aspecto ( $\left.\mathrm{AspP}_{\text {Progressivo }}\right)$. Nossa análise tomou por base o ordenamento dos núcleos funcionais proposto na hierarquia de Cinque (CINQUE, 1999, 2006; RIZZI; CINQUE, 2016).

Na primeira seção, apresentamos os diferentes conceitos associados aos dois tipos de obrigação: ought-to-be e ought-to-do. Na segunda, realizamos um mapeamento inicial da posição que os deônticos ought-to-be parecem ocupar na estrutura sintática das sentenças. Já na terceira, procuramos motivar a distinção entre os dois tipos de deônticos - e também suas diferenças em relação aos epistêmicos - em termos de traços sintáticos como agentividade [Ag] e asserção [Assert], assumindo que modais correspondem a um único item lexical (KRATZER, 1981, 2001, 2012) e que essas diferentes leituras derivam da posição em que ocorre a checagem desses traços.

\section{Diferentes conceitos de obrigação: ought-to-be e ought-to-do}

Feldman (1986) distingue dois tipos de obrigação: uma que configura um conjunto de normas de como um certo estado de coisas deve ser, o que está relacionado ao seu conceito de obrigação moral (ought-to-be); outra que recai sobre um indivíduo específico (ought-to-do). Trata-se de uma distinção entre uma regra moral abstrata e uma obrigação particularizada a um agente em potencial. Para ilustrar o primeiro 
caso, Feldman apresenta uma situação em que alguém, incomodado com o barulho de motos, enuncia:

(1) There ought to be a law against such things.

(Deveria existir uma lei contra essas coisas).

Um outro exemplo dado pelo autor para casos de interpretação ought-to-be são enunciados como:

(2) There ought to be a more equal distribution of wealth in the world.

(Deveria haver uma distribuição mais equitativa de riqueza no mundo).

Esses casos diferem daqueles que envolvem uma relação entre um indivíduo agente e um estado de coisas. O autor observa que, em uma situação como a de o barulho das motos estar importunando alguém, é possível também usar a noção de obrigação associada ao tipo ought-to-do, como em:

(3) The legislature ought to prohibit loud motorcycles.

(A legislatura deve proibir motos barulhentas).

Essa declaração estabelece uma conexão entre um agente (o conjunto que representa os legisladores) e uma ação possível (no caso, a proibição de motos barulhentas). Enquanto a interpretação ought-to-be envolve uma propriedade de um estado de coisas que deve ocorrer; a interpretação ought-to-do envolve a relação entre um agente particular e um estado de coisas. Neste último caso, é afirmada a obrigação vinculada a um agente explicitamente mencionado na sentença.

Brennan (1993), ancorada na distinção conceitual apresentada em Feldman (1986), associa apenas os deônticos do tipo ought-to-do ao evento descrito pelo VP. Isso porque tais deônticos são orientados para um dos participantes deste evento normalmente o sujeito da sentença, sobre quem recai a obrigação/permissão de fazer algo (ought/allowed-to-do) que resulte em um estado de coisas. A interpretação do tipo ought-to-be, segundo Feldman, remete ao modo como um estado de coisas deve ser: ought/allowed-to-be, não relacionando uma propriedade a um agente em particular, e sim a um estado de coisas.

As sentenças do exemplo a seguir, transcritas de Brennan (1993, p. 77), ilustram as duas leituras que podem ser associadas aos deônticos:

(4) a. You must register or else you'll get kicked out. (ought-to-do)

(Você deve se inscrever; caso contrário, será expulso)

b. Thesis paper must be acid-free. (ought-to-be)

(O papel da tese deve ser livre de ácido) 
A autora afirma que a sentença iniciada por 'or else '("caso contrário"), em (4a), dá um impulso pragmático para a interpretação ought-to-do ao modal. Já em (4b), a inanimacidade do sujeito nos força a assumir que há um constituinte não mencionado na sentença sobre o qual recai a obrigação de garantir que o papel da tese seja livre de ácido, licenciando, assim, a interpretação ought-to-be. Esse "agente oculto" de (4b) não precisa ser, todavia, um indivíduo específico, mas pode ser um indivíduo qualquer (ou mesmo um conjunto de indivíduos, como "os doutorandos"), desde que esteja saliente na situação de fala. As duas leituras disponíveis ao deôntico - ought-to-do e ought-to-be - podem ser associadas a uma única sentença, a depender dos indivíduos sobre os quais recai a obrigação, conforme mostra o exemplo (5):

\section{(5) João deve jantar às 19 horas.}

A sentença (5) pode ser interpretada como uma obrigação que recai sobre o próprio João - sujeito da sentença (leitura ought-to-do); ou como uma ordem direcionada a uma outra pessoa qualquer - (em geral) o interlocutor, que pode ser a babá de João, por exemplo, que é quem deve garantir que João realize o evento de jantar às 19 horas (leitura outht-to-be). Nesse caso, bem como em outras instâncias de deônticos oughtto-be, a regra moral abstrata é mencionada no curso da realização de um ato de fala diretivo, no qual o falante impõe a um ouvinte (ou, em casos menos prototípicos, a outro indivíduo contextualmente saliente) uma obrigação, baseada no seu desejo de que tal regra seja cumprida em uma situação particular - cf. a discussão sobre essa classe de atos de fala em Searle (1979).

Hacquard $(2006,2010)$ assume também a existência de dois tipos de deôntico. À semelhança de Brennan (1993), a autora associa cada uma das leituras (ought-to-do e ought-to-be) a posições sintáticas diferentes: uma baixa, logo acima do VP, em que o modal é orientado para o sujeito gramatical; e outra alta, acima dos núcleos de Tempo, em que o modal é orientado para um participante saliente no evento de fala, o addressee (interlocutor). A posição baixa é associada aos modais de raiz; e a posição alta, aos deônticos ought-to-be, juntamente com os epistêmicos. Hacquard estabelece, portanto, uma distinção estrutural relevante entre os diferentes tipos de modalidade. De acordo com a proposta da autora, são disponibilizados eventos diferentes em cada uma dessas posições, aos quais os operadores modais se relativizam: em posição baixa, os modais se relativizam ao evento descrito pelo VP; em posição alta, os modais se relativizam ao evento de fala.

A proposta da autora não dá conta, entretanto, de diferenciar estruturalmente os epistêmicos dos deônticos ought-to-be, considerando que ambos são modais altos, que acessam o evento de fala. Mostramos abaixo que o único contraste que a autora estabelece na estrutura é o correspondente à leitura deôntica ought-to-do e à epistêmica (HACQUARD, 2010, p. 7):

(6) a. $\left[_{\mathrm{CP}}\right.$ Speech $\left.\mathrm{e}_{0} \lambda \mathrm{e}_{0}\left[\mathrm{CP}_{\mathrm{TP}} \mathrm{T} \operatorname{Asp}_{1} \lambda \mathrm{e}_{1} \operatorname{Mod} \mathrm{f}\left(\mathrm{e}_{1}\right)\left[_{\mathrm{VP}} \mathrm{V} \mathrm{e}_{1}\right]\right]\right]$ (Deôntico)

b. $\left[{ }_{\mathrm{CP}}\right.$ Speech e $\left.\mathrm{e}_{0} \lambda \mathrm{e}_{0} \operatorname{Modf}\left(\mathrm{e}_{0}\right)\left[_{\mathrm{TP}} \mathrm{T} \mathrm{Asp}_{1} \lambda \mathrm{e}_{1}\left[_{\mathrm{VP}} \mathrm{V} \mathrm{e}_{1}\right]\right]\right]$ (Epistêmico) 
A representação que Hacquard propõe para os deônticos, em (6a), é compatível apenas com a interpretação em que a obrigação/permissão recai sobre o sujeito da sentença, ou seja, correspondente à leitura do tipo ought-to-do, em que a variável de evento na relação de acessibilidade do modal (f) está ligada ao evento descrito pelo VP $\left(\mathrm{e}_{1}\right)$. Essa variável precisa ser sempre ligada localmente, pelo operador mais próximo - no caso de (6a), Asp 1 ; e de (6b), um marcador ilocucionário Speech (ROSS, 1970; SPEAS, 2004). A autora reconhece a existência de um deôntico alto, que acessa o evento de fala e é orientado para o addressee, mas não especifica precisamente a posição em que este é interpretado, nem demarca suas diferenças em relação ao também alto - modal epistêmico.

Para Hacquard, modais correspondem a um único item lexical - à semelhança do que propõe Kratzer $(1981,2001,2012)$ - cuja leitura é especificada a partir da variável de evento à qual o modal se liga. Ao assumir que a especificação da leitura modal está relacionada também à determinada posição na estrutura, Hacquard se aproxima da proposta de Cinque, que prevê para cada interpretação modal uma posição fixa, conforme a hierarquia de núcleos funcionais transcrita em (7):

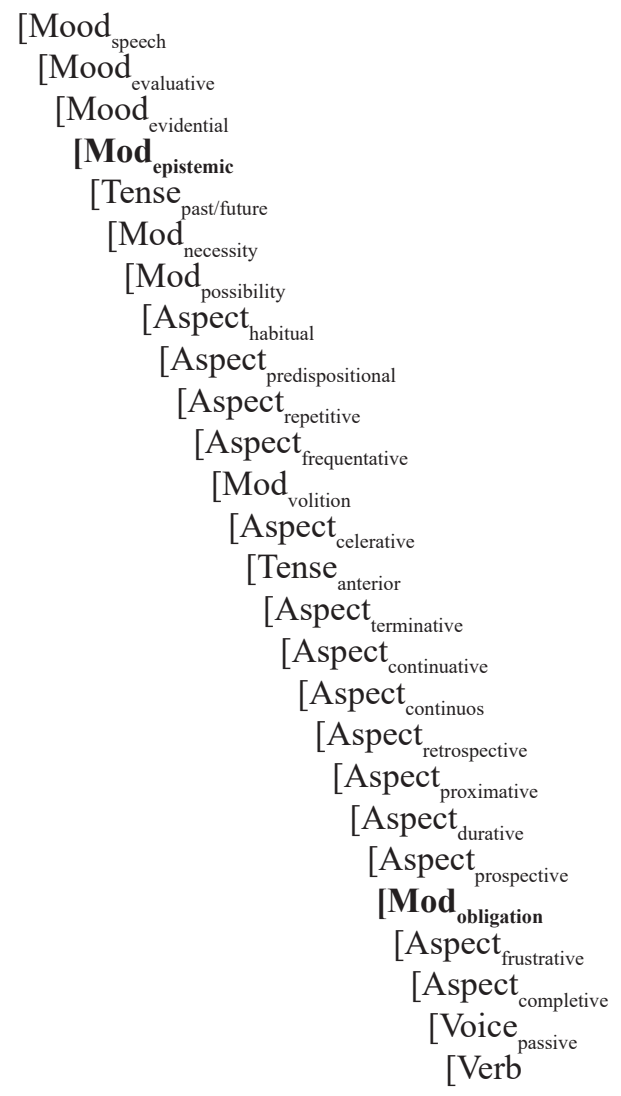

(RIZZI; CINQUE, 2016, p. 149, grifo nosso). 
A modalidade epistêmica ocupa as primeiras posições na hierarquia, figurando, inclusive, acima dos núcleos funcionais de tempo e aspecto. Já a modalidade deôntica ocupa uma posição baixa na hierarquia, bem próxima ao núcleo VoiceP.

Os estudos cartográficos, como o de Rizzi e Cinque (2016), objetivam estabelecer mapas detalhados da estrutura sintática de modo a oferecer instruções transparentes para o sistema de interface. É importante notar aqui que a hierarquia em (7) não captura as diferentes interpretações deônticas: ought-to-do e ought-to-be. Em princípio, teríamos aí uma distinção semântica sem paralelos na sintaxe, o que é anômalo nessa perspectiva, especialmente para predicados funcionais. Até onde sabemos, não há na literatura uma proposta de representação sintática que reconheça a interpretação deôntica do tipo ought-to-be. Conforme a hierarquia de núcleos funcionais transcrita em (7), na proposta cartográfica sequer é prevista uma posição alta para um deôntico. Nesse sentido, consideramos premente depreender as diferenças estruturais entre as leituras deônticas ought-to-do e ought-to-be, determinadas, pelo menos parcialmente, por fatores sintáticos, conforme Oliveira e Rech (2016), Rech e Varaschin (2017, 2018). Supomos que a distinção conceitual dos dois tipos de deôntico (FELDMAN, 1986) resulta de diferenças estruturais. Nossa pesquisa buscou mapear a posição em que o operador modal faz a checagem de traços que derivam as propriedades de um deôntico ought-to-be. Para isso, analisamos fatores como a orientação dos deônticos (o participante sobre o qual recai a ordem/obrigação ou permissão), sua relação com outros núcleos modais e também sua relação com categorias de tempo e aspecto ( $\left.\mathrm{AspP}_{\text {Progressivo }}\right)$, do que nos ocupamos na próxima seção.

\section{Um olhar para a estrutura sintática com enfoque no deôntico ought-to-be}

Neste estudo, analisamos os deônticos a partir da abordagem teórica de Hacquard (2006, 2010), segundo a qual os operadores modais são avaliados relativamente a eventos, e não a mundos. Isto é, a relação de acessibilidade de um modal - que delimita o conjunto de mundos sobre o qual ele quantifica - é determinada pelo evento ao qual ele se vincula na estrutura sintática da sentença. Para Hacquard, a posição do modal na estrutura está diretamente relacionada ao tipo de variável de evento que ele acessa: modais que operam sobre o evento de fala (speech event - $\mathrm{e}_{0}$ ) ocupam uma posição alta; já modais que operam sobre o evento principal, descrito pelo VP (VP event $-\mathrm{e}_{1}$ ) ocupam uma posição baixa. Cada um desses eventos se torna disponível em posições definidas na estrutura. De acordo com essa proposta, é esperado que a posição em que um modal se liga a uma variável de evento tenha reflexos não apenas no indivíduo sobre o qual recai a orientação do modal, mas também na sua interação com os núcleos de

tempo $\left(\mathrm{TP}_{\text {Past/Future }}\right)$ e aspecto, como o progressivo $\left(\mathrm{AspP}_{\text {Progressive }}\right)$. Modais que acessam localmente o ato de fala ocupam uma posição acima de TP e de $\mathrm{AspP}_{\text {Progressive }}$ na hierarquia de Cinque - com a qual a proposta de Hacquard dialoga; eles não pegariam, portanto, marcas flexionais de tempo e de aspecto progressivo. Em (8), transcrevemos a parte 
relevante da hierarquia de Cinque para a investigação das relações entre os núcleos modais - epistêmico (ModP $\mathrm{Epistemic})$ e deônticos $\left(\mathrm{ModP}_{\text {Obligation }}\right.$ e $\left.\mathrm{ModP}_{\text {Permission }}\right)$ - e as categorias de tempo $\left(\mathrm{TP}_{\text {Past/Future }}\right)$ e aspecto $\left(\mathrm{AspP}_{\text {Progressive }}\right)$ :

(8) Hierarquia das Projeções Funcionais:

MoodPspeech act $>$ MoodPevaluative $>$ MoodPevidential $>$ ModPepistemic $>$ $\mathrm{TP}($ Past $)>\mathrm{TP}($ Future $)>\ldots>$ AspPhabitual $>$ AspPrepetitive $(\mathrm{I})>\ldots>$ AspPproximative $>$ AspPdurative $>$ AspPprogressive $>$ AspPprospective $>$ AspPinceptive $>$ ModPobligation $>$ ModPability $>$ AspPfrustrative/success $>$ ModPpermission $>$ AspPconative $>$ AspPcompletive $($ I $)>$ VoiceP . . .

(CINQUE, 2006, p. 12, 93, grifo nosso).

Na hierarquia de Cinque, estão previstas duas posições para a interpretação de um núcleo modal deôntico (ModP ${ }_{\text {Obligation }}$ e ModP Permission ); é importante observar, contudo, que ambas se localizam em posição baixa na estrutura, depois do núcleo $\mathrm{AspP}_{\text {Progressive }}$ e próximas ao núcleo VoiceP. Esses deônticos correspondem, portanto, a modais de raiz e, por isso, esperamos que sejam orientados apenas para participantes do evento descrito pelo VP - preferencialmente o sujeito da sentença, uma vez que, pela sua posição na estrutura, não poderiam acessar participantes do evento de fala, como o addressee. $\mathrm{O}$ ordenamento dos núcleos funcionais que integram a hierarquia de Cinque foi depreendido a partir de testes de transitividade, que revelam a impossibilidade de alternância na ordem quando mais de um núcleo funcional coocorre na sentença. $\mathrm{O}$ exemplo (9) ilustra este ordenamento em construções com modais:

(9) a. João pode ter que morar em Paris.

$\left(* \operatorname{Mod}_{\text {Permission }}>\operatorname{Mod}_{\text {Obligation }}\right)$

b. João tem que poder morar em Paris.

$\left(\sqrt{ } \operatorname{Mod}_{\text {Obligation }}>\operatorname{Mod}_{\text {Permission }}\right)$

Em (9a-b), temos a alternância na ordem dos modais poder e ter que. Ambas as sentenças são bem formadas, entretanto, a interpretação deôntica está disponível para ambos os modais apenas quando o modal correspondente ao núcleo $\mathrm{Mod}_{\text {Obligation }}$ antecede o correspondente ao núcleo $\operatorname{Mod}_{\text {Permission, }}$ em (9b). Esse exemplo ratifica, portanto, o ordenamento proposto por Cinque na hierarquia: $\operatorname{ModP}_{\text {Obligation }}>\ldots>\operatorname{ModP}_{\text {Permission }}$. Mas, além disso, ele mostra que, quando ocorrem dois deônticos em uma mesma construção, o primeiro necessariamente é orientado para um indivíduo ou um grupo de indivíduos no evento de fala, enquanto o segundo é orientado para o sujeito da sentença. Neste caso, a sentença (9b) é empregada em contextos nos quais o falante coloca sobre alguém não mencionado (geralmente o interlocutor, mas podendo ser também o chefe de João, os diretores da empresa etc) a obrigação de garantir que João receba permissão para morar em Paris. Temos aí, portanto, uma das características marcantes dos deônticos altos, como veremos na próxima seção: o fato de eles figurarem na realização de um ato 
de fala diretivo direcionado a um agente em potencial na situação de fala (tipicamente ao ouvinte). ${ }^{1}$ Note que não é possível interpretarmos (9b) de modo que a ideia de obrigação e de permissão recaiam ambas sobre o mesmo participante: o sujeito da sentença (Pedro). Isso significaria algo como Pedro estar sendo obrigado a receber permissão para morar em Paris. Logo, parece, sim, haver um ordenamento rígido entre $\mathrm{ModP}_{\text {Obligation }}>\ldots>\mathrm{ModP}_{\text {Permission }}$, conforme prediz a hierarquia de Cinque, mas as diferentes orientações dos modais nestes casos - em que o de obrigação recai sobre um indivíduo na situação de fala, e o de permissão recai sobre o sujeito - sugerem que o deôntico de obrigação (ter que) não só está mais alto do que o de permissão (poder), mas ele está muito mais alto do que a posição que Cinque prevê para o núcleo $\operatorname{ModP}_{\text {Obligation, }}$ pois acessa agentes potenciais disponíveis no evento de fala, direcionando a algum deles um ato ilocucionário diretivo. (9b) configura, portanto, uma evidência em favor da postulação de um deôntico alto. ${ }^{2}$

Os exemplos (10) e (11), a seguir, mostram casos de sequência de deônticos que caracterizam o fenômeno de concordância modal, conforme Lunguinho (2010, p. 130-131):

(10) P: Professores da rede pública ganham benefícios como vale alimentação etc?

$\boldsymbol{R}:$ (...) Um dos benefícios que nós temos é plano de saúde médica onde todos os meses eles descontam $5 \%$ do nosso salário bruto. Ou seja, se quiser ser professor de algo você deve ter que adorar o seu conteúdo e ter muita, mas muita vontade de dar aulas...

(11) P: Queria ser piloto de helicóptero, que devo fazer? Gostaria de saber que grau de escolaridade precisa pra fazer um curso de piloto, preço do curso, carga horária e

\footnotetext{
"I believe that there is a fundamental distinction between these two types of deontics. Ought-to-do deontics are the kind captured in Kratzer's system via a circumstantial modal base (which picks out facts of the base world) and a deontic ordering source. Ought-to-be deontics, on the other hand, seem to double a modal statement with a performative act, namely, that of putting an obligation on the addressee." (HACQUARD, 2006, p. 41). O indivíduo sobre o qual recai a obrigação dos deônticos ought-to-be é tipicamente o ouvinte, pois o ouvinte é, juntamente com o falante, o indivíduo invariavelmente presente em todas as situações de fala.

2 É importante notar, contudo, que um deôntico alto pode estar associado também à noção de permissão, como em O Pedro pode atuar no setor de vendas. Essa sentença, além de poder ser empregada em contextos nos quais se faz o relato constativo de uma permissão dada ao Pedro (deôntico ought-to-do), pode ser interpretada como um ato de fala diretivo, em que o falante se dirige a alguém como o addressee, dando-lhe permissão para remanejar o Pedro na empresa (deôntico ought-to-be). A possibilidade de associar a interpretação ought-to-be à noção de permissão, como nesse exemplo, deveria gerar a ordem $\mathrm{ModP}_{\text {Permission }}>\mathrm{ModP}_{\text {Obligation }}$, desde que o primeiro modal fosse um deôntico ought-to-be. Esse ordenamento parece, entretanto, não ocorrer na língua, conforme o exemplo a seguir:
}

(i) O pai pode ter que visitar os filhos quinzenalmente.

A sentença (i) contrasta com (9b) no sentido de bloquear a interpretação deôntica para o primeiro modal da sequência. Observa-se, portanto, uma restrição à interpretação deôntica ought-to-be em contextos nos quais o modal de permissão antecede o de obrigação. Não imaginamos a razão para essa restrição, uma vez que um modal orientado para o addressee ocupa uma posição mais alta do que um modal orientado para o sujeito da sentença, seja este de obrigação ou de permissão. Além disso, não parece haver restrição de natureza pragmática para este ordenamento, visto que é possível imaginar um contexto no qual o falante concede uma permissão ao addressee para que este garanta o cumprimento de uma ordem. 
se é fácil conseguir um serviço de piloto, uma vez que tenha terminado o curso. Muito obrigado.

$\boldsymbol{R}$ : Deve ter que ter um grau de escolaridade avançado. No Campo de Marte na cidade de São Paulo, eles dão esse curso. Você pode se informar lá, se morar em SP.

Esse fenômeno se caracteriza por fazer com que dois itens modais realizados na sintaxe sejam interpretados como apenas um. Para que ocorra concordância modal, duas condições precisam ser satisfeitas: (i) pelo menos um dos elementos modais tem que ser um verbo auxiliar, podendo o outro elemento modal ser igualmente um verbo auxiliar ou, então, um advérbio; e (ii) os elementos modais devem compartilhar a mesma força modal e o mesmo tipo de modalidade. Nos exemplos (10) e (11), os elementos envolvidos compartilham a mesma força modal (universal) e o mesmo tipo de modalidade (deôntica); trata-se, portanto, de casos de concordância modal. Note-se que esses exemplos contrastam com (9b), que não manifesta os efeitos de concordância modal, mesmo exibindo uma sequência de deônticos. Com base na análise de Lunguinho, dados como ( $9 b$ ) não geram concordância modal, porque, embora os itens modais concordem quanto ao tipo de modalidade - ambos são deônticos -, eles não compartilham a mesma força modal: ter que é quantificador universal, e poder é existencial. O exemplo (12) ilustra mais um caso de sequência de núcleos modais:

\section{O contribuinte deve ter que pagar por mais este serviço.}

Em (12) também não se manifestam os efeitos de concordância modal. Isso porque os modais deve e ter que, mesmo compartilhando a mesma força quantificacional (universal), ${ }^{3}$ diferem quanto ao tipo de modalidade: deve é interpretado como epistêmico; e ter que como deôntico.

A partir de exemplos como os de (9) a (12), é possível depreender uma generalização: salvo em casos de concordância modal, a ocorrência de dois deônticos em uma mesma estrutura é possível apenas com o seguinte ordenamento: Ought-to-be $>$ Ought-to-do. O primeiro deôntico se liga ao evento de fala, em posição alta; logo, a ordem/obrigação recai sobre um indivíduo saliente no contexto de enunciação, normalmente o addressee. O segundo deôntico se liga ao evento descrito pelo VP, em posição baixa; neste caso, a orientação modal recai sobre um dos participantes deste evento, normalmente o sujeito da sentença.

A partir deste ponto, passamos a investigar o comportamento dos deônticos ought-to-be em relação à flexão de tempo e do progressivo. A sentença em (13), à semelhança do exemplo (5), mostra que um auxiliar modal com interpretação deôntica pode estar orientado tanto para o sujeito da sentença (deôntico do tipo ought-to-do) quanto para um provável addressee (deôntico do tipo ought-to-be):

\footnotetext{
A respeito do caráter dual do auxiliar deve no português brasileiro, ver Santos (2015). De acordo com essa autora, enquanto pode e ter que formam o par dual possibilidade-necessidade, deve é um modal gradual de força variável, oscilando em um intervalo que cobre tanto possibilidade quanto necessidade.
} 
Em um contexto usual, a sentença em (13) poderia ser interpretada como: (i) de acordo com as normas do banco, a obrigação de passar pela porta giratória recai sobre os clientes - deôntico do tipo ought-to-do; ou (ii) essa obrigação recai sobre o segurança responsável pelo controle da entrada dos clientes no banco, que é quem deve garantir que estes passem pela porta giratória - deôntico do tipo ought-to-be. No primeiro caso, a obrigação recai sobre um participante do evento descrito pelo VP (Os clientes do banco), que se realiza como sujeito da sentença; já no segundo caso, a ordem/obrigação recai sobre um participante do evento de fala (neste caso particular, o addreesse) ${ }^{4}$. O participante sobre o qual recai a orientação do modal é, portanto, uma importante distinção entre os deônticos do tipo ought-to-do e ought-to-be.

Os dois tipos de deôntico se distinguem também em relação ao tempo de avaliação. A sentença (13) está no tempo presente. Isso permite que seja interpretada como o relato de uma ordem (deôntico ought-to-do) ou como a realização de um ato de fala diretivo (deôntico ought-to-be). Essa dualidade de interpretação é licenciada porque a flexão do modal coincide, neste caso, com o tempo de fala. Se o modal estiver com marca de flexão no passado, por exemplo, a leitura ought-to-be será bloqueada. Este é um resultado esperado, visto que não se dá uma ordem para alguém realizar um evento no passado. A sentença (14) ilustra essa restrição:

(14) Os clientes do banco tiveram que passar pela porta giratória.

Supomos que a restrição à interpretação ought-to-be ocorre, em casos como o ilustrado em (14), por ser este um deôntico alto, que não está sob o escopo das categorias de tempo $\left(\mathrm{TP}_{\text {PastFuture }}\right)$, o que o impede de realizar movimento (não se assume movimento descendente na teoria) para acoplar-se à flexão T. Já o deôntico ought-to-do ocupa uma posição abaixo das categorias de tempo (CINQUE, 1999, 2006; STOWELL, 2004; HACQUARD, 2006, 2010; RIZZI; CINQUE, 2016), podendo, assim, realizar movimento para essas posições.

Outro indicativo de que os deônticos do tipo ought-to-be ocupam uma posição acima das categorias de tempo é evidenciado na má-formação da sentença (15b) a seguir:

(15) a. As crianças têm que poder fazer as refeições na escola.

b. *As crianças tiveram que poder fazer as refeições na escola.

Conforme afirmamos acima, nos casos de emparelhamento de deônticos em que não opera o fenômeno da concordância modal, o único ordenamento possível é

\footnotetext{
A interpretação ought-to-be remete ao modo como um estado de coisas deve ser, não relacionando diretamente uma propriedade a um agente definido (FELDMAN, 1986). Neste sentido, (13) determina que, segundo as normas do banco, é obrigatório que os clientes passem pela porta giratória. Essa obrigação recai genericamente sobre qualquer pessoa acessível na situação de fala. Como é geralmente função do segurança do banco controlar a entrada de clientes, no contexto mais usual para (13), a obrigação recairia sobre ele.
} 
Ought-to-be > Ought-to-do. Se, como vimos argumentando, o primeiro deôntico é necessariamente associado à leitura ought-to-be, a má-formação de (15b), em que este auxiliar modal exibe marca de passado, é esperada, ratificando a hipótese de que o deôntico ought-to-be ocupa uma posição acima das categorias de tempo.

A flexão de aspecto progressivo também dá indícios da posição que um auxiliar modal ocupa na estrutura. Os verbos que podem receber marca de aspecto progressivo são apenas aqueles c-comandados por $\mathrm{AspP}_{\text {Progressive }}$ (ver ordenamento dos núcleos funcionais em (8)). Todas as projeções abaixo deste núcleo admitirão que seu $\mathrm{V}$ funcional apareça na forma progressiva. Verbos funcionais que estejam acima de $\mathrm{AspP}_{\text {Progressive, }}$ por sua vez, não têm como receber essa marca. Logo, é esperado que o modal não incorpore a marca de progressivo quando corresponder a um deôntico ought-to-be. Os exemplos (16b) e (17b), a seguir, ilustram esta restrição:

a. O candidato ao intercâmbio está tendo que morar em Berlim.

b. *O candidato ao intercâmbio está tendo que ter origem germânica.

(17) a. A protagonista da série está podendo ser inconveniente com os outros atores.

b. *A protagonista da série está podendo ter menos de vinte e cinco anos.

As sentenças (16a) e (17a) são bem formadas com os deônticos de obrigação (ter que) e de permissão (poder) flexionados no aspecto progressivo. Esse resultado é o esperado, visto que tais verbos correspondem a deônticos do tipo ought-to-do, que ocupam uma posição baixa na estrutura e, consequentemente, são orientados para o sujeito da sentença. Essa leitura é possível, segundo Rech e Varaschin (2018), por os estados sob o escopo do modal (morar em Berlim e ser inconveniente com os outros atores) serem passíveis de controle ${ }^{5}$. De acordo com a nossa hipótese, a restrição ao aspecto progressivo deve atuar apenas sobre os deônticos do tipo ought-to-be, por eles ocuparem uma posição acima do AspP $P_{\text {Progressive }}$. As sentenças (16b) e (17b) mostram essa restrição, uma vez que ilustram um contexto em que apenas a interpretação deôntica do tipo ought-to-be é possível, qual seja: deônticos formando sequência com estativos não passíveis de controle com DPs atributivos (RECH; VARASCHIN, 2018). Como os deônticos aí só podem ser legitimamente interpretados como ought-to-be, o resultado de acoplar a flexão no progressivo ao modal exigiria um movimento descendente impossível: daí a anomalia da sentença.

Outro contexto sintático em que a única interpretação licenciada para o deôntico corresponde à do tipo ought-to-be é, como vimos acima, o de coocorrência de dois modais deônticos na estrutura, conforme (15), repetido abaixo como (19a):

\footnotetext{
Um predicado stage-level não licencia, necessariamente, a interpretação deôntica baixa (ought-to-do), como poderíamos supor a partir da boa formação dos exemplos (16a) e (17a). Predicados stage-level não passíveis de controle - como ficar ou estar doente/febril - oferecem restrições à interpretação ought-to-do, como evidencia a impossibilidade de flexão do modal no progressivo: *O candidato ao intercâmbio está tendo que ficar doente/febril. Isso mostra que a distinção relevante para a possibilidade de leitura deôntica baixa não é o contraste stage-level/ individual-level, mas sim a que há entre predicados controláveis e não-controláveis.
} 
(18) a. As crianças têm que fazer as refeições na escola.

$$
\left(\operatorname{Mod}_{\text {Obligation }}\right)
$$

b. As crianças estão tendo que fazer as refeições na escola.

(19) a. As crianças têm que poder fazer as refeições na escola.

$$
\left(\operatorname{Mod}_{\text {Obligation }}>\operatorname{Mod}_{\text {Pemission }}\right)
$$

b. *As crianças estão tendo que poder fazer as refeições na escola.

Na ocorrência de dois modais deônticos na estrutura, conforme (19a), o primeiro (ter que) será orientado para um participante do evento de fala (normalmente o addressee); enquanto o segundo (poder), para um participante externally-merged no evento de VP (normalmente o sujeito da sentença). Logo, o modal ter que corresponde nesse contexto, necessariamente, a um deôntico do tipo ought-to-be. Esta é a causa da má-formação de (19b), que mostra um deôntico alto com marca de aspecto progressivo. Observe que, em (18), o modal ter que corresponde a um deôntico baixo, cuja orientação recai sobre o sujeito da sentença (As crianças); neste caso, por ocupar uma posição mais baixa que a do núcleo $\mathrm{AspP}_{\text {Progressive }}$, pode receber tal marcação, como se depreende da boa formação de (18b).

Por fim, apresentamos exemplos que ilustram como os - também altos - modais epistêmicos reagem ao tempo e ao aspecto progressivo:
(20) a. João pode estar triste.
b. *João pôde estar triste.
c. *João está podendo estar triste.

Em (20a), estamos diante de um contexto sintático que oferece restrições à interpretação deôntica (RECH; VARASCHIN, 2018), tanto do tipo ought-to-do quanto ought-to-be, uma vez que sob o escopo do modal está um predicado estativo não passível de controle com DP referencial. Logo, a única interpretação disponível para pode nesta sentença é a epistêmica. A má-formação de (20b) e (20c) resulta justamente do fato de as marcas de tempo e de aspecto estarem associadas a um auxiliar modal epistêmico. Este corresponde a um modal alto na estrutura da sentença, localizando-se acima de TP e de AspP $P_{\text {Progressive }}$, conforme a hierarquia de núcleos funcionais transcrita em (8). Daí sua impossibilidade de flexão, tanto no passado quanto no progressivo, pois essas marcas de flexão só podem se ligar a núcleos que as seguem na hierarquia. Vimos que essa restrição pesa igualmente sobre os deônticos ought-to-be, revelando semelhanças entre estes e os modais epistêmicos em relação a fenômenos ligados à posição (altura) do modal. Outra similaridade relevante entre esses dois predicados funcionais diz respeito à sua circunstância de avaliação: ambos são avaliados relativamente ao evento de fala (HACQUARD, 2006) e orientados para um de seus participantes: deôntico ought-to-be é orientado, preferencialmente, para o addressee; e o epistêmico, para o falante. 
Na próxima seção, propomos distinguir, a partir de dois traços - agentividade $[ \pm \mathrm{Ag}]$ e asserção [ \pm Assert], deônticos ought-to-be de epistêmicos, ambos mapeados como modais altos na estrutura; e deônticos ought-to-be de deônticos ought-to-do, ambos associados ao conceito de obrigação/permissão.

\section{Traços associados à interpretação dos auxiliares modais: uma proposta inicial para distinguir a leitura deôntica ought-to-be da epistêmica e da deôntica ought-to-do}

Conforme observamos na seção 1, Hacquard (2006, 2010) não distingue estruturalmente o deôntico ought-to-be dos modais epistêmicos. As representações propostas pela autora (ver (6a-b) na seção 1) discernem apenas o deôntico do tipo ought-to-do do epistêmico. Essa distinção é estabelecida pela posição (altura) ocupada pelo modal na estrutura: deônticos ought-to-do ocupam posição baixa, acessando a variável de evento $e_{1}$, correspondente ao evento descrito pelo VP; já os epistêmicos ocupam uma posição alta na estrutura, acessando a variável de evento $e_{0}$, que corresponde ao evento de fala. É importante observar, contudo, que as propriedades que esta autora associa ao deôntico ought-to-be sugerem que este ocupa uma posição tão alta na estrutura quanto a do modal epistêmico.

Na seção 2, mostramos o comportamento desses núcleos em relação à orientação modal e à flexão de tempo e aspecto. Os epistêmicos são orientados para o falante; e os deônticos ought-to-be, tipicamente para o addressee, ambos participantes do evento de fala. Isso indica que tanto epistêmicos quanto deônticos ought-to-be ocupam posição alta na estrutura. Em relação à flexão de tempo e aspecto progressivo, mostramos que epistêmicos e deônticos ought-to-be sofrem as mesmas restrições, ratificando a hipótese de corresponderem, ambos, a modais altos na estrutura, ocupando posições acima das categorias de tempo $\left(\mathrm{TP}_{\text {Past/Future }}\right)$ e de aspecto $\left(\mathrm{AspP}_{\text {Progressive }}\right)$.

Não é novidade na literatura linguística que epistêmicos exibem tais propriedades. Esses modais são tratados como núcleos funcionais altos por autores como Cinque (1999, 2006), Stowell (2004), Hacquard (2006, 2010), Zagona (2007), Rizzi e Cinque (2016), entre outros. A questão que nos interessa particularmente é a posição ocupada pelos deônticos ought-to-be, que ainda são reconhecidos por poucos autores como um tipo de deôntico distinto do deôntico baixo ou de raiz. Considerando as semelhanças no comportamento dos núcleos epistêmicos e deônticos ought-to-be quanto à orientação do modal e a relações de escopo sobre as categorias de tempo e aspecto, cabe investigar se esses núcleos ocupam a mesma posição na estrutura da sentença, diferenciando-se apenas pela checagem de traços. Se este for o caso, é esperado que epistêmicos não coocorram com deônticos ought-to-be, o que passamos a investigar na sequência do artigo. Para isso, vamos, inicialmente, lançar mão de contextos de emparelhamento de deônticos em que não opera o fenômeno da concordância modal, como o de (21a): 
a. Carlos tem que poder cantar.

(Ought-to-be > Ought-to-do)

b. * Carlos pode ter que poder cantar.

c. *Possivelmente, Carlos tem que poder cantar.

A agramaticalidade das sentenças (21b) e (21c) valida a hipótese de que epistêmicos e deônticos ocupam a mesma posição na estrutura, visto que dá indícios da impossibilidade de coocorrência desses núcleos em uma mesma sentença. Em (21a), uma das leituras licenciadas para ter que é a correspondente ao deôntico ought-to-be; neste caso, poder é associado a um dêontico baixo (ought-to-do), podendo também licenciar uma leitura de habilidade - o que não está em foco neste artigo. A má-formação das sentenças (21b) e (21c) nos permite inferir que o núcleo epistêmico não está acima do deôntico alto, uma vez que não é possível a inserção de um auxiliar modal epistêmico (poder), em (22b), nem a de um advérbio epistêmico, em (21c), acima do primeiro verbo auxiliar deôntico (ter que), o qual é orientado para um agente no evento de fala (geralmente o addressee). A partir de (21), propomos que a ordem modal epistêmico seguido de deôntico ought-to-be não é possível:

$$
* \operatorname{Mod}_{\text {Epistêmico }}>\operatorname{Mod}_{\text {Deo Ought-to-be }} \text {. }
$$

Note que, se associarmos o modal ter que a um deôntico ought-to-be em (21a), a leitura epistêmica não será licenciada ao verbo poder, apenas uma leitura de raiz: permissão ou capacidade. Esse resultado sugere que um ordenamento inverso ao de (22), como em (23), também não é gerado na língua:

$$
\text { * } \operatorname{Mod}_{\text {Deo Ought-to-be }}>\operatorname{Mod}_{\text {Epistêmico }} \text {. }
$$

Por conta disso, temos de considerar a hipótese de epistêmicos e deônticos ought-to-be ocuparem a mesma posição na estrutura. A proposta de Hacquard sinaliza nesta direção, à medida que, excluindo os casos de sentenças encaixadas, prevê apenas duas variáveis de evento às quais os modais podem ser relativizados: uma em posição alta $\left(\mathrm{e}_{0}\right)$; e outra em posição baixa $\left(\mathrm{e}_{1}\right)$. Além disso, as propriedades relacionadas ao deôntico ought-to-be (ver seção 2) sugerem que este núcleo acessa o evento de fala, à semelhança dos epistêmicos. Logo, parece ser o caso que deônticos ought-to-be e epistêmicos concorram à mesma variável e ocupem a mesma posição. Isso explicaria a impossibilidade de figurarem juntos em uma sentença. Este cenário nos coloca outra questão: se epistêmicos e deônticos ought-to-be ocupam a mesma posição na estrutura e acessam a mesma variável de evento (HACQUARD, 2006), quais são e como são derivadas as propriedades que distinguem esses núcleos modais?

Nossa proposta vai na direção de considerar o modal como um único item lexical cujas especificidades estão atreladas à posição em que este núcleo faz a checagem de traços que determinam sua interpretação. Um aspecto importante a considerar nessa 
discussão é que as posições previstas para cada um dos núcleos funcionais modais na hierarquia de Cinque não representam, necessariamente, a posição de interpretação do modal, e sim a posição de concatenação (external merge), em que, numa perspectiva como a da Hacquard, estaria acessível uma variável de evento cujas propriedades especificariam a leitura modal.

De acordo com Oliveira e Rech (2016) e Rech e Varaschin (2017, 2018), os deônticos - tanto ought-to-be quanto ought-to-do - precisam checar o traço agentivo [+Ag] com um dos participantes do evento ao qual o modal é relativizado. Se o modal for concatenado em posição baixa na estrutura, o evento acessível a ele será o descrito pelo VP $\left(\mathrm{e}_{1}\right)$. Para a checagem do traço [ $+\mathrm{Ag}$ ], é necessário que esteja disponível neste evento um participante agentivo; logo, é esperado que deônticos ought-to-do formem sequência com predicados lexicais inergativos e transitivos (que selecionam um agente) e ofereçam restrições a inacusativos e estativos (que selecionam argumentos sem este traço). ${ }^{6}$ Esse requerimento do modal explica por que a leitura ought-to-do não é disponibilizada em (24b):

a. O Pedro deve viajar ainda este mês.

b. O Pedro deve morrer ainda este mês.

Em (24a), o modal deve pode receber tanto interpretação epistêmica quanto deôntica (ought-to-be ou ought-to-do). De acordo com nossa hipótese, a interpretação ought-to-do é licenciada ao modal porque há um participante agentivo ( $O$ Pedro) no evento descrito pelo VP. É com este participante que o modal irá checar o seu traço [+Ag], necessário para derivar a leitura deôntica. Em (24b), a interpretação ought-to-do não é disponibilizada. Supomos que essa restrição se deve às propriedades do predicado sob o escopo do modal, que é um inacusativo que não descreve deslocamento em espaço físico; logo, não há no evento descrito pelo VP nenhum participante $[+\mathrm{Ag}]$ com o qual o deôntico possa checar seu traço. A interpretação ought-to-be está, todavia, disponível para o modal em (24b). Essa sentença pode ser interpretada, e.g., como uma ordem ao addressee para que este garanta que o evento de Pedro morrer ainda este mês se realize. Neste caso, o deôntico faria a checagem do traço [+Ag] com um participante agentivo no evento de fala (o addressee), relativizando-se ao evento $e_{0}$ (HACQUARD, 2010).

O núcleo modal epistêmico não requer um participante agentivo, como se depreende das sentenças do exemplo a seguir:

Oliveira e Rech (2016), em estudo de natureza experimental, constataram que falantes do português brasileiro aceitam leitura deôntica ought-to-do em contextos nos quais o modal forma sequência com inacusativos que descrevem deslocamento físico (chegar, entrar, sair, surgir, aparecer,...), mas rejeitam esta leitura com os demais inacusativos (nascer, morrer, murchar, florescer,...). Rech e Varaschin $(2017$; 2018) explicam como a interpretação deôntica ought-to-do é licenciada com alguns predicados inacusativos e também com estativos passíveis de controle. 

a. Pode chover.
b. Essas flores podem murchar logo.
c. O Pedro deve ser de origem germânica.

Nas sentenças do exemplo (25), apenas a leitura epistêmica está disponível para os modais poder e dever. O predicado sob o escopo do modal em cada uma dessas sentenças não seleciona argumento agentivo: em (25a), trata-se de um verbo que não seleciona argumentos; em (25b), o predicado corresponde a um inacusativo que não descreve deslocamento físico; e, por fim, em (25c), o predicado encaixado é um estativo não passível de controle, que oferece restrições a deônticos ought-to-do (RECH; VARASCHIN, 2018). Nesses casos, não há um participante agentivo no evento descrito pelo VP que possa checar o traço $[+\mathrm{Ag}]$ de um deôntico; logo, a restrição à interpretação ought-to-do já era esperada. É interessante observar aqui que, para esses casos, a interpretação deôntica ought-to-be também não está disponível ao modal. Em (25a), a restrição parece resultar da ausência de um participante agentivo a quem pudesse ser dada a permissão para que o evento chover aconteça. Já em (25b) e (25c), os predicados sob o escopo do modal não são passíveis de controle; neste caso, não é possível dar uma ordem ou permissão para alguém controlar um evento que não pode ser controlado. ${ }^{7}$

A partir do traço [+Ag] parece, portanto, ser possível distinguir deônticos (ought-to-be e ought-to-do) de epistêmicos, visto que apenas os primeiros requerem um participante agentivo.

$\mathrm{O}$ traço $[+\mathrm{Ag}]$ não nos permite, entretanto, distinguir entre os tipos de dêontico. Como já mencionamos nas seções 1 e 2 , o deôntico ought-to-be é tipicamente empregado no curso de um ato ilocucionário diretivo, uma vez que é licenciado em contextos nos quais o falante dá uma ordem/permissão a um participante do evento de fala, tipicamente o addressee. Já o deôntico ought-to-do figura em contextos nos quais se faz o relato de uma ordem/permissão que recai sobre um dos participantes do evento descrito pelo $\mathrm{VP}$ - normalmente o sujeito da sentença. As sentenças em (26) ilustram essa diferença:

a. Deve ter bem-casado na recepção.

b. Os responsáveis pelo buffet tiveram que colocar bem-casado na recepção.

Em (26a), é licenciada a interpretação deôntica ought-to-be ao modal deve. Neste caso, a sentença corresponde a um ato de fala diretivo endereçado a alguém na ocasião

\footnotetext{
É importante frisar que não estamos considerando contextos "roteirísticos", em que mesmo um nome próprio como Pedro em (25c) pode assumir uma leitura atributiva, veiculando um sentido metalinguístico parafraseável como "o indivíduo/personagem/homem chamado "Pedro"'. Essa leitura seria favorecida se (25c) constasse no texto de uma peça de teatro. Nesses casos, se o DP sujeito fosse interpretado atributivamente, a leitura ought-to-be seria possível. O que nos interessa aqui, todavia, é a combinação peculiar de um estado não-controlável com um DP referencial, visto que, nesses contextos (RECH; VARASCHIN, 2018), o ouvinte não teria como atuar, nem diretamente sobre a propriedade (dado que se trata de uma propriedade não-controlável), nem sobre a seleção de um referente que satisfaça a propriedade (o que pode ocorrer quando o DP é atributivo).
} 
de enunciação e o modal está ancorado no tempo do evento de fala (Speech time). Já em (26b), a leitura ought-to-be não está disponível. O modal carrega marca de flexão de passado e corresponde ao relato de uma ordem, e não a um ato de fala diretivo, propriedades associadas ao deôntico ought-to-do. Logo, uma propriedade relevante para distinguir entre os dois tipos de deôntico parece ser a de que apenas o deôntico ought-to-do figura em sentenças meramente assertivas. Nesse sentido, o traço sintático asserção [Assert], associado por Zagona (2007) aos epistêmicos, pode ser estendido aos deônticos do tipo ought-to-do. Assim, com apenas dois traços - agentividade [Ag] e asserção [Assert] - é possível diferenciar epistêmicos de deônticos ought-to-be e também estes últimos dos deônticos ought-to-do, como mostramos no Quadro 1 a seguir:

Quadro 1 - Traços associados aos núcleos modais epistêmicos e deônticos

\begin{tabular}{|l|c|c|c|}
\hline Mraços & Epistêmico & $\begin{array}{c}\text { Deôntico } \\
\text { Ought-to-be }\end{array}$ & $\begin{array}{c}\text { Deôntico } \\
\text { Ought-to-do }\end{array}$ \\
\hline Agentividade $[\mathrm{Ag}]$ & {$[-\mathrm{Ag}]$} & {$[+\mathrm{Ag}]$} & {$[+\mathrm{Ag}]$} \\
\hline Asserção [Assert] & {$[+$ Assert $]$} & {$[$-Assert $]$} & {$[+$ Assert $]$} \\
\hline
\end{tabular}

Fonte: Elaboração própria.

Conforme sistematizamos no Quadro 1, o modal epistêmico se diferencia dos dois tipos de deôntico pelo traço agentividade. Já para diferenciar os deônticos ought-to-be e ought-to-do, estamos propondo o traço asserção [Assert]. Essa matriz simplificada de traços pode ser um caminho para explicar como modais que ocupam a mesma posição na estrutura licenciam diferentes leituras, sem ter de postular que essa diferença está demarcada no léxico. Estamos considerando aqui que ela é dada ao longo da derivação.

\section{Considerações finais}

Constatamos que uma distinção conceitual refinada como a que Feldman (1986) estabelece entre uma obrigação ought-to-be e ought-to-do encontra reflexos sintáticos bastante sistemáticos e robustos. Por meio de testes - que exploravam resultados independentemente motivados a respeito da posição de outros núcleos funcionais (CINQUE, 2006) e de propriedades de predicados lexicais (RECH; VARASCHIN, 2017, 2018) - procuramos fornecer evidências da existência de um deôntico alto (ought-to-be) no português brasileiro.

Supomos que a principal contribuição do nosso artigo é apresentar propriedades sintáticas que estão associadas apenas à interpretação deôntica do tipo ought-to-be, dando suporte a análises que localizam este tipo de modalidade em uma posição alta na estrutura (BRENNAN, 1993; HACQUARD, 2006, 2010). Para além disso, consideramos ter contribuído para o avanço dos estudos dos modais sob uma perspectiva sintática 
ao depreender evidências de que deônticos ought-to-be e epistêmicos compartilham propriedades que nos levam a supor que são concatenados em uma mesma posição na estrutura. Sugerimos que o que especifica as leituras desses itens é uma diferença na checagem de traços: o deôntico ought-to-be seria [+Ag] e [-Assert]; e os epistêmicos seriam [-Ag] e [+Assert]. Pelo traço asserção, mostramos ser possível também distinguir entre as duas interpretações deônticas.

Estamos cientes de que a descrição que apresentamos aqui é uma pequena contribuição aos estudos sobre modalidade no português brasileiro. A nossa atenção se centrou em como um dos tipos de modalidade - a deôntica ought-to-be - é derivado na estrutura. Nossa pesquisa não especifica exatamente essa posição, mas auxilia no seu mapeamento, ao mostrar como esse tipo de deôntico se relaciona com categorias como tempo e aspecto (progressivo). Julgamos ser preciso avançar na descrição dessas relações para avaliar se a proposta da Hacquard — de que modais são interpretáveis relativamente a eventos acessíveis em certas posições na estrutura - é de fato compatível com o mapeamento das categorias funcionais descrito por Cinque. Como vimos, esse modelo cartográfico parece se aplicar aos modais do português brasileiro, exceto por ainda não reconhecer uma posição alta para o deôntico ought-to-be, objeto desta pesquisa.

\section{Agradecimentos}

Agradecemos ao CNPq pelo auxílio (Processo 424025/2016-7), concedido pelo Edital Universal 01/2016.

RECH, N.; VARASCHIN, G. Properties of the Ought-to-be Deontic Modal. Alfa, São Paulo, v.62, n.2, p.361-380, 2018.

- ABSTRACT: In this article, we discuss different concepts of obligation based on the distinction originally established by Feldman (1986): (i) ought-to-be interpretation, which involves a property that a certain state of affairs must occur; and (ii) ought-to-do interpretation, which relates an agent to a state of affairs. We assume this conceptual distinction results from structural differences. In this line of argument, we follow authors like Brennan (1993) and Hacquard (2006, 2010). Since there isn't yet a proposal of structural representation in the literature that contemplates the ought-to-be interpretation, we searched for evidence in Brazilian Portuguese to ascertain more precisely the position at which this deontic is structurally merged in order to generate its interpretation. We scrutinized factors such as the deontic's orientation, its relation to other modal heads and also to tense and aspect categories. Our tests confirmed the existence of a high deontic (ought-to-be). This particular modal displays the properties of a directive speech act, being oriented towards an agent in the speech situation (usually the addressee), and it does not bear aspect or tense markers. Even though ought-to-be deontics don't share all of these properties with the epistemics, there is 
evidence that they occupy the same position in the structure. Lastly, we also suggested that ought-to-be, ought-to-do deontics and epistemics can be distinguished on the basis of two features: agentivity [Ag] and assertion [Assert].

- KEYWORDS: Deontic Modality. Ought-to-be Deontics. Cinque's hierarchy. Feature checking.

\section{REFERÊNCIAS}

BRENNAN, V. M. Root and epistemic modal auxiliary verbs. 1993. 455f. Thesis (Ph.D. in Linguistics) - University of Massachusetts, Amherst, 1993.

CINQUE, G. Restructuring and functional heads: the cartography of syntactic structures. New York: Oxford University Press, 2006. v.4.

CINQUE, G. Adverbs and functional heads: a cross-linguistic perspective. New York: Oxford University Press, 1999.

CINQUE, G.; RIZZI, L. The cartography of syntactic structures. STiL: Studies in Linguistics (CISCL Working Papers), [S.1.], v. 2, p. 42-58, 2008.

FELDMAN, F. Doing the best We can. Dortrecht: Reidel, 1986.

HACQUARD, V. On the event relativity of modal auxiliaries. Natural Language Semantics, [S.1.], v.18, n.1, p. 79-114, 2010. Disponível em: <http://ling.umd. edu// hacquard/papers/hacquard_NALS_eventrelativity.pdf $>$. Acesso em: 12 de janeiro de 2017.

HACQUARD, V. Aspects of modality. 2006. 214f. Tese (Doctor of Philosophy in Linguistics) - Massaschusetts Institute of Technology, Cambridge, 2006.

JACKENDOFF, R. Semantic interpretation in generative grammar. Cambridge: MIT, 1972.

KRATZER, A. Modals and conditionals. NewYork: Oxford University Press, 2012.

KRATZER, A. Modality. In: VON STECHOW, A.; WUNDERLICH, D. (Ed.). Semantik: ein internationales handbuch zeitgenössischer forshhung. Berlin: Mouton de Gruyter, 2001. p.639-650.

KRATZER, A. The notional category of modality. In: EIKMEYER, H-J.; RIESER, H. (Org.). Word, worlds, and contexts: new approaches to word semantics. Berlin: W. de Gruyter, 1981. p. 38-74.

LUNGUINHO, M. V. Sobre a concordância modal em português. Cadernos de Linguagem e Sociedade, Brasília, v. 11, p. 117-140, 2010.

PALMER, F. R. Mood and modality. Cambridge: Cambridge University Press, 2001. 
OLIVEIRA, R. P.de.; RECH, N. F. Flavors of obligation: the syntax/semantics of deontic deve in Brazilian Portuguese. Letras de Hoje, Porto Alegre, v.51, n.3, p. 349-357, 2016. RECH, N. F.; VARASCHIN, G. Predicados estativos e os tipos de deôntico: ought-to-do e ought-to-be. Cadernos de Estudos Linguísticos, Campinas, v. 60, n. 1, p. 159-177, 2018.

RECH, N. F.; VARASCHIN, G. Predicados inacusativos e a modalidade deôntica. Revista Letras, Curitiba, n. 96, p. 219-238, 2017.

RIZZI, L.; CINGUE, G. Functional categories and syntactic theory. Annual Review of Linguistics, [S.1.], v. 2, p. 139-163, 2016.

ROSS, J. R. On declarative sentences. In: JACOBS, R. A.; ROSENBAUM, P. S. (Org.). Readings in english transformational grammar. Waltham: Ginn \& Co, 1970. p. 222-277.

SANTOS, A. L. P. Força e evidência: uma análise teórico experimental da semântica de 'pode', 'deve' e 'ter que'. 2015. 277f. Tese (Doutorado em Linguística) - Universidade Federal de Santa Catarina, Florianópolis, 2015.

SEARLE, J. R. A taxonomy of illocutionary acts. In: SEARLE, J. R. Expression and meaning: studies in the theory of speech acts. Cambridge: Cambridge University Press, 1979.

STOWELL, T. Tense and modals. In: GUÉRON, J.; LECARME, J. (Org.). The syntax of time. Cambridge: MIT, 2004. p. 621-635.

SWEETSTER, E. From etymology to pragmatics: metaphorical and cultural aspects of semantic structure. Cambridge: Cambridge University Press, 1990.

SPEAS, M. Evidentiality, logophoricity and the syntactic representation of pragmatic features. Lingua, [S.1.], v. 114, n. 3, p. 255-276, 2004.

ZAGONA, K. On the syntactic features of epistemic and root modals. In: EGUREN, L.; FERNÁNDEZ-SORIANO, O. (Org.). Coreference, modality and focus. Amsterdam: Benjamins, 2007. p. 221-236.

Recebido em 4 de agosto de 2017

Aprovado em 12 de abril de 2018 